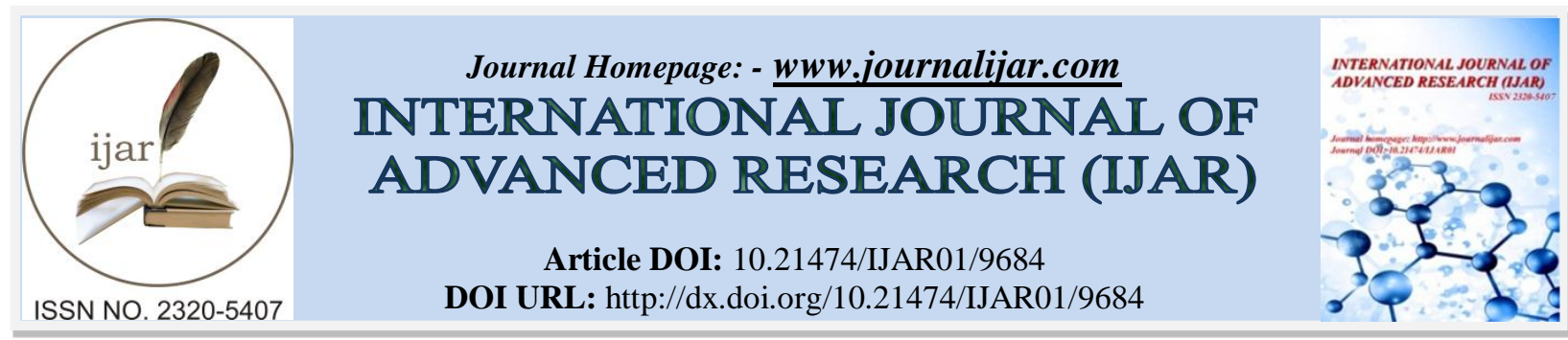

RESEARCH ARTICLE

\title{
ROLE OF SHATAVARI IN MANAGEMENT OF EARLY OSTEOARTHRITIS.
}

Dr. Pooja S.K.Rai ${ }^{1}$, Dr.Kanchan Sonone ${ }^{2}$ and Dr. Pramod Ingale ${ }^{3}$.

1. Associate Professor, Department of Biochemistry, Lokmanya Tilak Municipal Medical College \& Hospital, Sion Mumbai.

2. Assistant Professor, Department of Biochemistry, Lokmanya Tilak Municipal Medical College \& Hospital, Sion Mumbai.

3. Professor \& Head, Department of Biochemistry, Lokmanya Tilak Municipal Medical College \& Hospital, Sion Mumbai.

\section{Manuscript Info}

Manuscript History

Received: 06 July 2019

Final Accepted: 08 August 2019

Published: September 2019

Key words:-

Shatavari, Osteoarthritis, Calcium ,Vitamin D, phosphorus, Alkaline phosphatase.

\section{Abstract}

Introduction: Osteoarthritis (OA) is most common form of progressive and degenerative joint disease that results from breakdown of joint cartilage and underlying bone. It has been one of the primary causes of morbidity in elderly population, affecting their social and mental health due to the pain associated with degeneration. Vitamin D plays important role in calcium and phosphorus homeostasis, which in turn are responsible for strength of bones \& cartilages. ALP is an enzymatic marker for bone metabolism, levels being predominantly increased in osteoblastic activity . Although there are multiple causes of osteoarthritis, deficiency of vitamin D, hypocalcemia \& hypophosphatemia are predominantly responsible for pathophysiology of osteoarthritis. It is also characterized by increased ALP activity.

Shatavari (Asparagus racemosa Linn) is considered to have antioxidant, anti-inflammatory, immunomodulator, soothing, cooling, and lubricating influence on the body. In the present study effect of shatavari in patients of early osteoarthritis have been studied.

Aim \& Objectives:Clinical \& biochemical evaluation of early osteoarthritis patients before \& after Shatavari treatment.

Material and methods: 30 patients of early osteoarthritis were clinically evaluated by orthopedic consultant by pain score and mobility of joints. Baseline blood sample was collected for estimation of S. Calcium, Phosphorus, ALP and Vit D. All patients were treated with Shatavari (Formulation prepared by ayurvedic medical college \& hospital) at dosage of $3 \mathrm{gms}$ OD for 2 months. Clinical \& biochemical evaluation were repeated 15 days after the last dose of shatavari.

Results: Result obtained were statistically analyzed by using paired $t$ test. Post treatment analysis of samples showed significant $(\mathrm{p}<0.05)$ increase in Calcium, Vitamin D and decrease in Alkaline phosphatase levels whereas difference in serum phosphorus was statistically insignificant.

Conclusion: It can be concluded that Shatavari treatment has beneficial effect on the patients of early Osteoarthritis \& should be included as a routine treatment in management of such patients.

Corresponding Author:-Dr. Pooja S.K.Rai. Address:-Associate Professor, Department of Biochemistry, Lokmanya Tilak Municipal Medical College 


\section{Introduction:-}

Osteoarthritis (OA) is a chronic degenerative disease characterized by the loss of cartilage due to destruction, which results in chronic pain leading to compromised mobility and reduced quality of life ${ }^{(1)}$. Osteoarthritis of knee joint contributes to nearly $80 \%$ of total osteoarthritis burden and it majorly affects the quality of life. In India, increase in number of elderly due to increase in Life expectancy is observed in recent years; hence, the problem of osteoarthritis is also increased. It is estimated around the world indicate that, of the men and women aged more than 60 years, $9.6 \%$ and $18 \%$ of them have symptomatic OA respectively ${ }^{(2)}$. Osteoarthritis related associated with hip as well as knee were ranked to be the 11th major contributors to world-wide disability, resulting in non-fatal conditions as burdens. This also adds up to $25 \%$ of all the visits to a physician and $50 \%$ of NSAIDs (non-steroidal antiinflammatory drugs) prescribed ${ }^{(3)}$.

Alkaline Phosphatase (ALP) is a hydrolase enzyme and removes phosphate groups from molecules such as nucleotides, proteins, etc. Bone and calcifying cartilage tissues express ALP which is observed on the cell surface and within matrix vesicles. Therefore, ALP is the most frequently used biomarker in detection of osteoblastic bone formation. Moreover, the level of ALP indicates that there can be active bone formation occurring as ALP is a byproduct of osteoblast activity ${ }^{(4)}$

Osteoarthritis is characterized by progressive loss of cartilage, whereas vitamin $\mathrm{D}$ has been shown to reduce cartilage degradation ${ }^{(5-6)}$

racemosus (Shatavari) is a climbing plant consisting of tuberous roots. According to Indian pharmacopoeia, A. racemosus contains not less than 0.1 per cent of Shatavarin IV, as calculated on the dried weight basis . The taste is initially starchy and then slightly bitter followed by a sweet taste.racemosus has small pin-needle like phylloclades (photosynthetic branches) which are uniform and shiny green in appearance. ${ }^{(7)}$

The primary outcome of Shatavari is analgesic, anti-inflammatory, chondroprotection, soft tissue healing, antiosteoporosis, immune-modulation, anti-lipogenesis, anabolic effect, and anti-oxidative stress. The secondary outcome of Ayurvedic antiarthritis drugs and regimen are to improve digestion and metabolism, normalize the gut function and clear bowel movement.$^{(8-10)}$

This is expected to rise to a level of becoming an important public health issue in due time, owing to the increase in obesity levels and sedentary life-styles. This could add to the burden when considered from the perspective of developments in developing nations, where life expectancy is expected, which could be hindered by unavailability of arthroplasty techniques and joint replacement facilities.

\section{Aim \& Objectives:-}

1. Clinical \& biochemical evaluation of early osteoarthritis patients before \& after Shatavari treatment.

2. To find out improvement in clinical and biochemical parameters after treatment with shatavari.

3. To conclude utility of shatavari in management of early osteoarthritis.

\section{Material and methods:- \\ Study period \& population:}

30 patients aged between 40 to 70 years of early osteoarthritis (grade 0-2) were clinically evaluated by orthopedic consultant by pain score and mobility of joints.

\section{Sample Collection before \& after treatment with Shatavari:}

Baseline blood sample was collected for estimation of S. Calcium, Phosphorus, ALP and Vit D. Serum levels of Calcium (by Arsenazo) ${ }^{(1)}$, Phosphorus (by Phosphomolybdate) ${ }^{(12)}$, ALP (by Deutsche Gesellschaft Fur Klinische Chemie (DGKC-SCE) ${ }^{(13)}$ and Vit D ( by chemiluminescence) ${ }^{(14)}$ method. All patients were treated with Shatavari (Formulation prepared by ayurvedic medical college \& hospital at dosage of 3 gms OD with warm water in empty stomach in the morning for 2 months. Clinical \& biochemical evaluation were repeated 15 days after the last dose of shatavari. 


\section{Inclusion criteria:}

From Grade 0-2

Subjective - Symptoms mentioned in text will be assessed at each follow up. Symptoms will be arbitrarily graded into 5 grades (0-4) on basis of severity.

Table No.1:-Grading of Osteoarthritis

\begin{tabular}{|c|c|c|c|c|}
\hline Grade & Knee Joint Pain & Restricted Motility & Crepitus & Edema of Knee \\
\hline 0 & No pain & No pain & No Crepitus & No Swelling \\
\hline 1 & Mild pain & $\begin{array}{l}\text { Pain without } \\
\text { winching of face }\end{array}$ & Palpable Crepitus & Slight Swelling \\
\hline 2 & $\begin{array}{l}\text { Moderate pain but } \\
\text { no difficulty in } \\
\text { walking }\end{array}$ & $\begin{array}{l}\text { Pain with winching } \\
\text { of face }\end{array}$ & Audible Crepitus & Moderate Swelling \\
\hline 3 & $\begin{array}{l}\text { Slight difficulty in } \\
\text { walking due to pain }\end{array}$ & $\begin{array}{l}\text { Prevent complete } \\
\text { flexion }\end{array}$ & & Severe Swelling \\
\hline 4 & $\begin{array}{l}\text { Severe difficulty in } \\
\text { walking }\end{array}$ & $\begin{array}{l}\text { Does not allow } \\
\text { passive movement }\end{array}$ & & \\
\hline
\end{tabular}

\section{Exclusion criteria:}

1. Rheumatoid arthritis

2. Joint replacements in both knees

3. Unable to walk without assistance

\section{Methodology:-}

Case- control study

Statistical analysis:

By using paired $t$ test

\section{Results:-}

Table 2:-Comparison of Early osteoarthritis patients before and after treatment with shatavari

\begin{tabular}{|l|l|l|l|l|}
\hline S.No & Parameter & Before treatment & After Treatment & P value \\
\hline 1 & Vitamin D $(\mathrm{ng} / \mathrm{ml})$ & $15.99 \pm 4.29$ & $33.28 \pm 13.37$ & $<0.05$ \\
\hline 2 & Alkaline phosphatase $(\mathrm{mg} / \mathrm{dl})$ & $320.33 \pm 45.61$ & $205.83 \pm 54.83$ & $<0.05$ \\
\hline 3 & Calcium $(\mathrm{mg} / \mathrm{dl})$ & $8.87 \pm 0.73$ & $9.59 \pm 0.77$ & $<0.05$ \\
\hline 4 & Phosphorus $(\mathrm{mg} / \mathrm{dl})$ & $3.73 \pm 0.4$ & $3.73 \pm 0.4$ & $>0.05$ \\
\hline
\end{tabular}

Table 2 shows that Post treatment analysis of samples showed significant $(\mathrm{p}<0.05)$ increase in Calcium $(8.87 \pm 0.73$ to $9.59 \pm 0.77)$,Vitamin D $(15.99 \pm 4.29$ to $33.28 \pm 13.37)$ and decrease in Alkaline phosphatase $(320.33 \pm 45.61$ to $205.83 \pm 54.83)$ levels whereas difference in serum phosphorus was statistically insignificant $(3.73 \pm 0.4, p>0.05)$.

\section{Discussion:-}

The present study revealed significant decrease in the levels of Vitamin D in study subjects $(\mathrm{p}<0.05)$. Our results were corroborated with Bassiouni et $\mathrm{al}^{(15)}$, Veronese et al ${ }^{(16)}$ and Jansen and Haddad ${ }^{(17)}$ found that serum 25(OH)D levels were significantly decreased in the patients with knee OA and noted that medial meniscal deterioration was seen in patients with low vitamin D levels.

Konstari et al ${ }^{(18)}$ found that vitamin D deficiency is associated with decreased cartilage thickness. Malas et al ${ }^{(19)}$ found that vitamin D deficiency significantly decreased femoral cartilage thickness in women between 20 and 45 years of age.

Zhang et al ${ }^{(20)}$ found that individuals with similar characteristics who were deficient in vitamin D and who were assessed radiographically for OA had an increased risk for OA of the knee, as assessed by radiologists blinded to the study. In a cross-sectional study with age-matched controls, 
Heidari et al ${ }^{(21)}$ and Goula et al ${ }^{(22)}$ found that a significant percentage of men and women who were vitamin D deficient had an increased prevalence of hip and knee arthritis based on radiologic assessment. It has been shown that patients with OA have decreased vitamin D serum levels. In our study, calcium levels are significantly decreased in Osteoarthritis, whereas alkaline phosphatase levels are significantly increased as compared to control subjects.

Our findings matches with Van Staa et al \& Manrique F et al studies which has reported that the concentrations of serum calcium and phosphorus are usually reduced, and serum ALP activity was elevated in Osteoarthritis. (23), (24)

Singla et al ${ }^{(25)}$ studied importance of Asparagus racemosus, having numerous activities such as hyperlipidemia, hypertension, angina, dysmenorrhea, anxiety disorders, benign prostatic hyperplasia (BPH), leucorrhoea and urinary tract infections. This plant possesses a wide range of secondary metabolites inclusive of steroids, alkaloids, dihydrophenanthrene derivatives, flavonoids, furan derivatives and essential oils. Information from the literature suggests that, the major constituents of A. racemosus are steroidal saponins which are mainly responsible for different biological activities of A. racemosus. They found the vitamin $\mathrm{C}, \mathrm{A}, \mathrm{E}, \mathrm{K}$ along with high Calcium levels in Root $(\mathrm{mg} / \mathrm{kg})(961.0 \pm 0.6$ to $2115.0 \pm 3.2) \&$ in Leaves $(\mathrm{mg} / \mathrm{mg})(1346.0 \pm 0.3$ to $6153.0 \pm 1.6)$.

\section{Conclusion:-}

From this study it can be concluded that shatavari being having anti-inflammatory \& possesses wide range of fat and water soluble vitamins may prevent inflammation in osteoarthritic patients.

Thus, Shatavari treatment has beneficial effect on the patients of early Osteoarthritis \& should be included as a routine treatment in management of such patients.

\section{Bibliography:-}

1. Feelisch M. The chemical biology of nitric oxide--an outsider's reflections about its role in osteoarthritis. Osteoarthritis Cartilage. 2008;16 Suppl 2:S3-S13.

2. Woolf A. D., Pfleger B. Burden of major musculoskeletal conditions. Bull World Health Organ. 2003;81(9):646-56.

3. Shuckett Mannal Hasan; Rhonda. Clinical features and pathogenetic mechanism of osteoarthritis. BC Medical Journal. 2010;52(8):6.

4. Golub EE. Role of matrix vesicles in biomineralization. Biochem Biophys Acta. 2009; 1790: $1592-8$.

5. McAlindon T, LaValley M, Schneider E, Nuite M, Lee JY, Price LL etal. Effect of vitamin D supplementation on progression of knee pain and cartilage volume loss in patients with symptomatic osteoarthritis: a randomized controlled trial. JAMA. 2013 Jan 9;309(2):155-62.

6. Holick MF High prevalence of vitamin D inadequacy and implications for health. Mayo Clin Proc. 2006 Mar;81(3):353-73.

7. Gomase V and Sherkhane A: Isolation, structure elucidation and biotransformation studies on secondary metabolites from Asparagus racemosus. Int J Microbiol Res 2010; 2:7-9.

8. Chopra A, Saluja M, Tillu G, Sarmukkaddam S, Venugopalan A. Ayurvedic medicine offers a good alternative to glucosamine and celecoxib in the treatment of symptomatic knee osteoarthritis: a randomized, double-blind, controlled equivalence drug trial. Rheumatology 2013;52:1408-17.

9. Subramoniam A, Madhavachandran V, Gangaprasad A. Medicinal plants in the treatment of arthritis. Annals of Phytomedicine 2013;2: 3-36.

10. Claudia M Witt, Michalsen A, Roll S, Morandi A, Gupta S. Comparative effectiveness of a complex Ayurvedic treatment and conventional standard care in osteoarthritis of the knee-study protocol for a randomized controlled trial, Trials 2013;14:149.

11. Tietz, N., Clinical Guide to Laboratory Tests, W.B. Saunders Company, Philadelphia $3^{\text {rd }}$ ed 1983; $5: 384$.

12. Z Klin. Chem Klin Biochem.1980;8:658.

13. Tietz N.W. Clinical Guide on Laboratory Tests. W.B. Saunders Company, Philadelphia $3^{\text {rd }}$ ed $1995 ; 286$.

14. Dynal AS. Access 25(OH) Vitamin D TOTAL Assay Package Insert, REF B24838, Oslo, Norway C06543AA.

15. Bassiouni H, Aly H, Zaky K, Abaza N, Bardin T. Probing the relation between vitamin D deficiency and progression of medial femoro-tibial osteoarthitis of the knee. Ann Rheum Dis. 2015;74:368-9.

16. Veronese N, Maggi S, Noale M, et al. Serum 25-hydroxyvitamin D and osteoarthritis in older people: the Progetto Veneto Anziani study. Rejuvenation Res. 2015;18:543-53. 
17. Jansen JA, Haddad FS. High prevalence of vitamin D deficiency in elderly patients with advanced osteoarthritis scheduled for total knee replacement associated with poorer preoperative functional state. Ann R Coll Surg Engl. 2013;95:569-72.

18. Konstari S, Kaila-Kangas L, Jaaskelainen T. Serum 25- hydroxyvitamin D and the risk of knee and hip osteoarthritis leading to hospitalization: a cohort study of 5274 Finns. Rheumatology. 2014;53:1778-1782.

19. Malas FU“ , Kara M, Aktekin L, Erso“z M, O” zc, akar L. Does vitamin D affect femoral cartilage thickness? An ultrasonographic study. Clin Rheumatol. 2014;33:1331-4.

20. Zhang FF, Driban JB, Lo GH . Vitamin D deficiency is associated with progression of knee osteoarthritis. J Nutr. 2014;144: 2002-8.

21. Heidari B, Heidari P, Hajian-Tilaki K. Association between serum vitamin D deficiency and knee osteoarthritis. Int Orthop. 2011;35: 1627-31.

22. Goula T, Kouskoukis A, Drosos G. Vitamin D status in patients with knee or hip osteoarthritis in a Mediterranean country. J Orthop Traumatol. 2015;16:35-39.

23. Van Staa TP, Geusens P, Bijlsma JW, Leufkens HG, Cooper C. Clinical assessment of the long-term risk of fracture in patients with rheumatoid arthritis. Arthritis Rheum 2006;54:3104-12.

24. Manrique F, Gamardo J, Elguezabal K, Martinis R, Castro JS, Bellorin-Font E, et al. Abnormalities of bone mineral density and bone metabolism in Venezuelan patients with rheumatoid arthritis. J Clin Rheumatol 2003;9:219-27.

25. Singla R and Jaitak V: Shatavari (Asparagus racemosus Wild): A review on its cultivation, morphology, phytochemistry and pharmacological importance. Int J Pharm Sci Res 2014; 5(3): 742-57. 